Tropical Journal of Pharmaceutical Research June 2017; 16 (6): 1293-1297

ISSN: $1596-5996$ (print); 1596-9827 (electronic)

(C) Pharmacotherapy Group, Faculty of Pharmacy, University of Benin, Benin City, 300001 Nigeria.

All rights reserved.

Available online at http://www.tjpr.org

Original Research Article

http://dx.doi.org/10.4314/tjpr.v16i6.12

\title{
Inhibitory effect of rhubarb on intestinal a-glucosidase activity in type 1 diabetic rats
}

\author{
KJ Hou*, CJ Lin, C Chen, BT Wu, XH Wang and D Zhu \\ Traditional Chinese Medicine Hospital of Shantou, Affiliated Hospital of Traditional Chinese Medicine University of Guangzhou, \\ Shantou City, China \\ *For correspondence: Email: kaijianhou@126.com
}

Revised accepted: 5 May 2017

\begin{abstract}
Purpose: To investigate the inhibitory effect of rhubarb on $\alpha$-glucosidase activity in the small intestine of rats with type 1 diabetes.

Methods: Type 1 diabetic rat model was established by intraperitoneally injecting 30 male SD rats with $1 \%$ streptozocin (STZ). Rats with fasting blood glucose $>11 \mathrm{mmol} / \mathrm{L}$ (24) were used for the study. The rats were randomly divided into three equal groups including control, acarbose and rhubarb groups. Arcabose $\Theta(20 \mathrm{mg} / \mathrm{kg} /$ day) and rhubarb (100 mg/ $/ \mathrm{kg} /$ day) were given by intra-gastric route via insertion of the cannula through the esophagus. Daily fasting blood glucose and daily postprandial glucose levels were assayed for all groups. On day 6, postprandial blood glucose, blood levels of C-peptide and insulin, and intestinal a-glucosidase were also determined.

Results: There were no significant differences in levels of C-peptide, insulin and fasting blood glucose between control, Acarbose $\circledast$ and rhubarb groups ( $p>0.05)$. However, $\alpha$-glucosidase activity at $0,30,60$ and 120 min in the rhubarb group was 1759.2, 1812.8, 1379.8 and $772.1 \mathrm{U}$, respectively,) while in the Acarbose $\AA$ group it was $178.6,1260.1,1126.5,599.2 \mathrm{U}$, respectively. $\alpha$-Glucosidase activity in both groups initially showed an increase $(p<0.05)$, followed by a decline from 60 to $120 \mathrm{~min}(p<0.05)$. After $120 \mathrm{~min}, \alpha$-glucosidase activity in each of the two groups was significantly decreased compared with untreated control $(1200 \mathrm{U})(p<0.05)$.

Conclusion: The inhibitory effect of rhubarb on intestinal $\alpha$-glucosidase activity of Type 1 diabetic rats is comparable to that of Arcabose $\Theta$. This suggests that this plant may have clinically potent anti-diabetic properties.
\end{abstract}

Keywords: Type 1 diabetes, $\alpha$-Glucosidase activity, Acarbose ${ }^{\circledR}$, Rhubarb, Postprandial glucose level

Tropical Journal of Pharmaceutical Research is indexed by Science Citation Index (SciSearch), Scopus, International Pharmaceutical Abstract, Chemical Abstracts, Embase, Index Copernicus, EBSCO, African Index Medicus, JournalSeek, Journal Citation Reports/Science Edition, Directory of Open Access Journals (DOAJ), African Journal Online, Bioline International, Open-J-Gate and Pharmacy Abstracts

\section{INTRODUCTION}

As a serious and chronic metabolic disorder, diabetes mellitus can be reflected by the increased levels of hemoglobin, fasting blood glucose and postprandial blood glucose [1]. Diabetic patients manifest impaired glucose tolerance which is a consequence defects in the function or secretion of insulin. Impaired glucose tolerance results in postprandial hyperglycemia [2]. The a-glucosidase inhibitors (Miglitol ${ }^{\circledR}$,
Voglibose $^{\circledR}$ and Acarbose $^{\circledR}$ ) are used for improving insulin sensitivity and decreasing postprandial hyperglycemia, through suppressing intestinal absorption of carbohydrates [3]. Type 1 diabetes, which is caused by insulin deficiency can be treated with a-glucosidase inhibitors [4]. Acarbose $^{\circledast}$ is a popular $\alpha$-glucosidase inhibitor [5]. a-Glucosidase activity has unique advantages in the treatment of diabetes mellitus, especially in reducing postprandial blood glucose. Acarbose ${ }^{\circledR}$ treatment, which is 
recommended by Asia Pacific Diabetes Drug Guide, is the first-line therapy of postprandial blood glucose reduction [6].

However, the use of Acarbose ${ }^{\circledR}$ is associated with problems of intolerance. In some patients, it produces intestinal problems, one of which is flatulence [7]. Therefore, the development of novel drugs with high activity and low mammalian toxicity is urgently needed. In this regard, the high and efficacy of herbs-derived drugs have attracted more and more attentions [8]. With the antibacterial, anti-tumor, antimutagenic and purgative activities, dried rhubarb rhizome was widely used in the traditional Chinese medicine. The main bioactive constituents of rhubarb are anthraquinone derivatives, which can induce apoptosis, inhibit cellular proliferation and prevent metastasis [9]. However, the anti-diabetic properties of rhubarb have not been well studied [10].

This study was carried out to investigate the effects of rhubarb on intestinal a-glucosidase and other indices (postprandial blood glucose, Cpeptide protein, insulin and fasting blood glucose) in an SD rat model of type 1 diabetes.

\section{EXPERIMENTAL}

\section{Materials}

Rhubarb (fine powder, Batch no. 110757200206; Xiankangwei Biological Engineering Co., Ltd. China) was preserved at room temperature. Acarbose (H19990205) was a product of Bayer Healthcare Pharmaceutical Company, Beijing. Alpha-glucosidase activity reagent (MAK123) was purchased from Sigma-Aldrich (St. Louis, MO, USA). Streptozoticin (STZ, $1 \%$ was prepared in $0.1 \mathrm{~mol} / \mathrm{L}$ citric acid buffer, $\mathrm{pH} 4.3$, was and preserved at $4{ }^{\circ} \mathrm{C}$.

\section{Animal model}

Thirty healthy male SD rats (mean weight $=$ $171.2 \pm 8.6 \mathrm{~g}$ ) were provided by Guangdong Medical Experimental Animal Center (China). The rats were kept in SPF animal house in Guangdong Medical Experimental Animal Center (license number: SYXK (Guangdong 2013-0002). They were housed in numbered cages in a room with a $10 \mathrm{~h} \mathrm{light} / 14 \mathrm{~h}$ dark cycle at $23 \pm 3{ }^{\circ} \mathrm{C}$ and moisture level of $55 \pm 15 \%$. Pellet feed containing $33.9 \%$ starch, and water were provided ad libitum. The rats were fasted overnight $(12 \mathrm{~h})$ and given intraperitoneal injection of $1 \% \mathrm{STZ}$ solution $(6 \mathrm{~mL} / \mathrm{kg}$ body weight). After 7 days, the fasting blood glucose of the rats was measured after $5 \mathrm{~h}$ fast. Rats with fasting blood- glucose $\geq 11.0 \mathrm{mmol} / \mathrm{L}$ were chosen as experimental models. This research was approved by the Animal Ethics Committee of Guangdong Provincial experimental Animal Center (approval ref no. B201504-9). All the animal experiments were performed according to "Guidelines for Ethical Conduct in the Care and Use of Animals" [11].

\section{Animal experiments}

Twenty-four model rats were randomly divided into control group (given saline), Acarbose group, and rhubarb group. Each group had 8 rats. In the acarbose group, rats were subjected to intragastric administration of $20 \mathrm{mg}$ Acarbose ${ }^{\mathrm{R}} / \mathrm{kg}$ body weight/day. Rats in the rhubarb group received $100 \mathrm{mg}$ rhubab/kg body weight/day, also via the intra-gastric route through insertion of the cannula via the esophagus, the dose were determined according the previous studies $[12,13]$. In both groups, the dose selection was based on estimated intake for a $60 \mathrm{~kg}$ reference man. In the control group, rats received intragastric saline once a day. Treatments for all groups were given at the same time. Rats in all groups were monitored physical changes and general performance. Each rat was weighed every two days, and the weight was recorded. Pelleted feed and clean drinking water were provided ad libitum throughout the period of study (7 days).From day one to day six, fasting blood-glucose determined daily after $4 \mathrm{~h}$ fast, after which feeding was restored. Then postprandial glucose was assayed. Water supply was not disrupted at any stage of the study. On the $7^{\text {th }}$ day, fasting and postprandial (30 min, 60 $\mathrm{min}$ and $120 \mathrm{~min}$ ) blood glucose, as well as C peptide insulin and intestinal a-glucosidase activities were determined.

\section{Assay of $\alpha$-glucosidase activity}

The rats were sacrificed under anaethesia, and the intestinal contents were cleared. The mucous membrane lining of the small intestine was carefully scraped onto an ice plate, and added to phosphate buffer, $\mathrm{pH} 6.8$ in a volume ratio of $5: 1$ (buffer : mucous membrane lining) at $4{ }^{\circ} \mathrm{C}$. The mixture was centrifuged $(5000 \mathrm{rpm})$ at $4{ }^{\circ} \mathrm{C}$ for $20 \mathrm{~min}$, and the supernatant was preserved at -20 ${ }^{\circ} \mathrm{C}$ prior to use in the assay of $\alpha$-glucosidase activity. The enzyme was assayed with SigmaAldrich kits (Art. No. MAK123) according to manufacturer's instructions.

\section{Assay of C-peptide and insulin}

Serum $C$ peptide and insulin were determined by enzyme-linked immunosorbate assay (ELISA). 


\section{Statistical analysis}

Statistical significance was evaluated by one-way ANOVA using SPSS 21 (SPSS Institute, Cary, NC, USA). $P<0.05$ was set as statistically significant.

\section{RESULTS}

There were no significant differences in fasting blood glucose, C-peptide and insulin between groups $(p>0.05)$ (Figure 1, Figure 2 and Figure $3)$. In addition, no significant difference was found in postprandial glucose levels between the groups at $120 \mathrm{~min}$ after feeding from days 1 to 7 $(p>0.05$, Figure 3B).

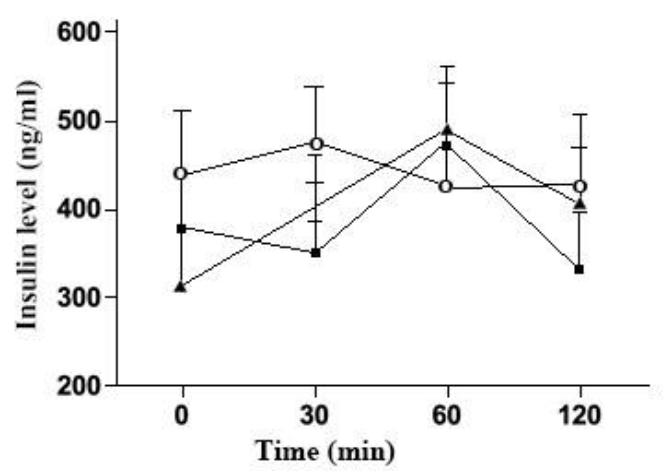

Figure 1: Insulin levels of the three groups. Key: $\mathbf{O}$ Control, - Acarbose, $\boldsymbol{\Delta}$ Rhubarb

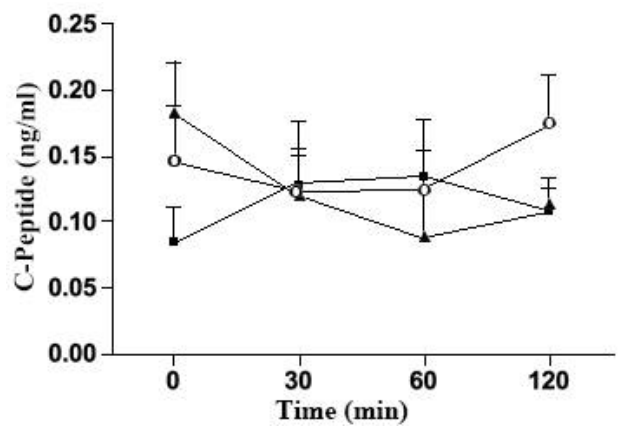

Figure 2: C-Peptide levels in the three groups. Key: $\mathbf{O}$ Control, $\mathbf{a}$ Acarbose, $\boldsymbol{\Delta}$ Rhubarb

In addition, there were no significant differences in postprandial glucose $120 \mathrm{~min}$ after feeding from day 1 to day $6(p>0.05)$ (Figure 3B). However, intestinal $\alpha--$ glucosidase activity results at $0,30,60$ and $120 \mathrm{~min}$ in the rhubarb group (1759.2, 1812.8, 1379.8 and $772.1 \mathrm{U}$, respectively) and acarbose (1759.2, 1260.1, 1126.5 and $599.2 \mathrm{U}$, respectively) groups showed initial increase from time zero to $30 \mathrm{~min}$, followed by significant decline from $60 \mathrm{~min}$ to 120 $\min (p<0.05)$. After $120 \mathrm{~min}, \alpha$-glucosidase activity in each of the two groups was significantly lower than control value $(1200 \mathrm{U})(p$ $<0.05)$.

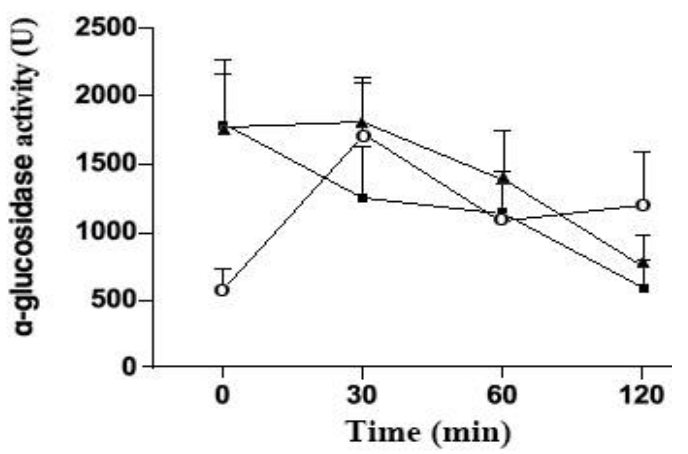

Figure 4: Intestinal a-glucosidase activities in the three groups. Key: $\mathbf{O}$ Control, $\mathbf{a c a r b o s e , ~}$ Rhubarb
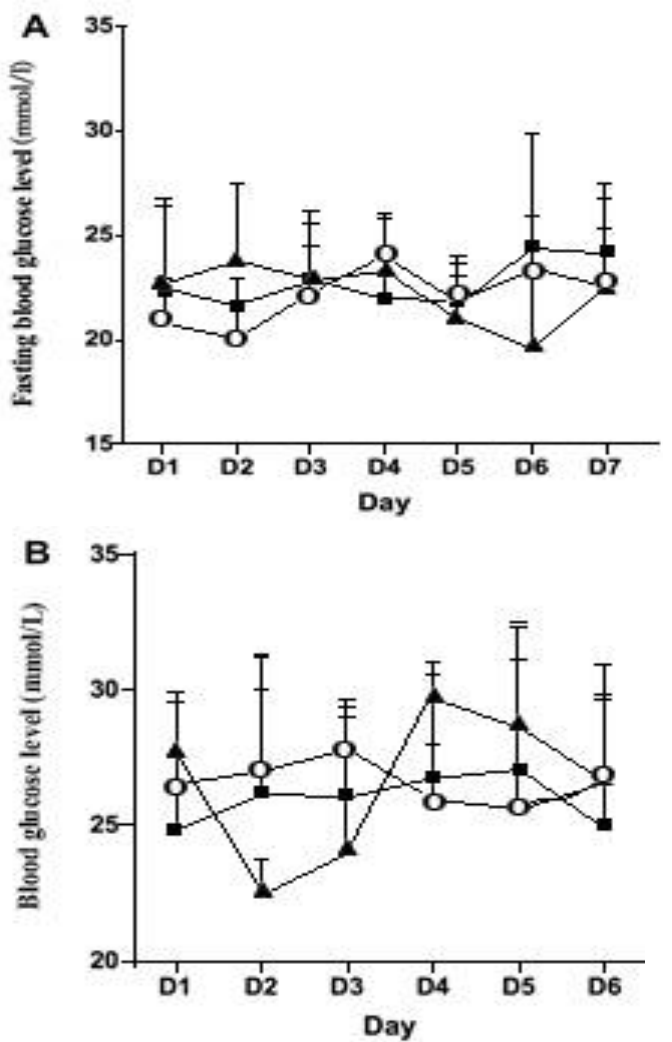

Figure 3: $\mathbf{A}=$ Comparison of daily fasting blood glucose levels among the three groups ; $\mathrm{B}=$ Comparison of postprandial blood glucose levels of the four groups 120 minutes after meals from Day 1 to Day 6. Key: $\mathbf{O}$ Control, $\boldsymbol{\square}$ Acarbose, $\boldsymbol{\Delta}$ Rhubarb

\section{DISCUSSION}

Prior to the administration of rhubarb and Arcabose, fasting blood glucose levels of rats in three groups were all $\geq 11.0 \mathrm{mmol} / \mathrm{L}$, and their insulin or C-peptide levels were not related to feeding. Most of the rats had damaged islet cells and hypoinsulinism. These data indicate that type 1 diabetes model was successfully established in the rats.

Treatment with rhubarb and Acarbose brought about significant reduction in the activity of 
postprandial intestinal $\alpha$-glucosidase. It is interesting to note that there was no significant difference in a-glucosidase activity between the rhubarb and Acarbose groups. This implies that rhubarb has the same level of efficacy as Acarbose. Thus rhubarb could be developed into a new type of hypoglycemic agent with similar $\alpha$ glucosidase inhibitory activity. This will have the advantage of overcoming the gastrointestinal discomfort usually associated with use of Acarbose $^{\mathrm{R}}$ [4].

The inhibitory effect of rhubarb may be due to anthroquiones, which are its major phytochemical components. Strangely, the activity of $\alpha$-glucosidase of rats in these two groups was abnormally higher than those of rats in the control group. Further studies are needed to verify whether this phenomenon was due to rebound effect or not.

Pipataline, sesamin, and pellitorine, which inhibit the activity ofa-glucosidase, have been applied in the prevention and treatment of diabetes [15]. Many plants in traditional Chinese medicine can significantly inhibit $\alpha$-glucosidase. MCQ et al have carried out a prospective study on the treatment of type 2 diabetes with natural chemical compounds extracted from plants instead synthetic a-glucosidase activity inhibitors [16]. Studies have shown that the anthroquinones in rhubarb inhibit $\alpha$-glucosidase activity in competitively $[16,17]$. The results obtained in this study further confirm that rhubarb possesses $\alpha$-glucosidase inhibitory activity.

Some studies have shown that the changes in the composition of intestinal microflora may be the primary cause of $\alpha$-glucosidase activity inhibition. For example, Streptomyces bacteria [18] and fermented black bean [19] have been reported as inhibitors of a-glucosidase activity. Thus it is not unlikely that the inhibition brought about by rhubarb might be linked, partially at least, to changes in composition of intestinal flora.

\section{CONCLUSION}

The inhibitory effect of rhubarb extract on intestinal a-glucosidase, which was comparable to that of acarbose, confirms the anti-diabetic potential of rhubarb. This finding is significant in the light of efforts to find replacement drugs with similar efficacy but less toxicity than Acarbose in the treatment of type 1 diabetes.

\section{DECLARATIONS}

\section{Acknowledgement}

The authors thank Key Scientific Projects of Shantou City for financial support (no. C201400126) and Laboratory Animal Center of Guangzhou Province for technical support.

\section{Conflict of Interest}

No conflict of interest associated with this work.

\section{Contribution of Authors}

The authors declare that this work was done by the authors named in this article and all liabilities pertaining to claims relating to the content of this article will be borne by them.

\section{Open Access}

This is an Open Access article that uses a funding model which does not charge readers or their institutions for access and distributed under the terms of the Creative Commons Attribution License (http://creativecommons.org/licenses/by/ 4.0) and the Budapest Open Access Initiative (http://www.budapestopenaccessinitiative.org/rea d), which permit unrestricted use, distribution, and reproduction in any medium, provided the original work is properly credited.

\section{REFERENCES}

1. Frontoni S, Di Bartolo P, Avogaro A, Bosi E, Paolisso G, Ceriello $A$. Glucose variability: An emerging target for the treatment of diabetes mellitus. Diabetes Res Clin Pract 2013; 102(2): 86-95.

2. Huang PL, Diabetes Mellitus and the Metabolic Syndrome, in MGH Cardiology Board Review. 2014, Springer. 120-132.

3. Min SW, Han JS. Polyopes lancifolia extract, a potent $\alpha$ glucosidase inhibitor, alleviates postprandial hyperglycemia in diabetic mice. Prev Nutr Food Sci2014; 19(1): 5-9.

4. Yilmazer-Musa M, Griffith AM, Michels AJ, Schneider E, Frei $B$. Grape seed and tea extracts and catechin 3gallates are potent inhibitors of $\alpha$-amylase and $\alpha$ glucosidase activity. JAgric Food Chem 2012; 60(36): 8924-8929.

5. Safavi M, Foroumadi A, Abdollahi M. The importance of synthetic drugs for type 2 diabetes drug discovery. Expert Opin Drug Discov 2013; 8(11): 1339-1363.

6. Madsbad S. Impact of postprandial glucose control on diabetes-related complications: How is the evidence evolving? J Diabetes Complications 2015; 30(2):374385 .

Trop J Pharm Res, June 2017; 16(6): 1296 
7. Kumar P, Vgm P. A Randomized Double-Masked Study of $50 \mathrm{mg}$ of Acarbose versus $0.2 \mathrm{mg}$ Voglibose in Overweight Type 2 Diabetes Patients Age Between 30 and 50 Years Having Isolated Postprandial Glycemia. Indian JClin Pract 2014; 24(9).

8. Patel $D$, Kumar $R$, Laloo $D$, Hemalatha $S$. Natural medicines from plant source used for therapy of diabetes mellitus: An overview of its pharmacological aspects. Asian Pac J Trop Dis 2012; 2(3): 239-250.

9. Huang $Q, L u G$, Shen $H M$, et al. Anti-cancer properties of anthraquinones from rhubarb. Medicinal research reviews, 2007, 27(5): 609-630.

10. Dong L-C, Fan Y-X, Yu Q, Ma J, Dong X, Li P, Li H-J. Synergistic effects of rhubarb-gardenia herb pair in cholestatic rats at pharmacodynamic and pharmacokinetic levels. J Ethnopharmacol 2015; 175: 67-74.

11. American Psychological Association. Guidelines for ethical conduct in the care and use of animals. J Exptal Anal Behav 1986, 45(2): 127.

12. Doğan A, Çelik I. Healing effects of sumac (Rhus coriaria) in streptozotocin-induced diabetic rats[J]. Pharmaceut Biol, 2016, 54(10): 2092-2102.

13. Jin JH, Ngoc TM, Bae $K H$, et al. Inhibition of Experimental Atopic Dermatitis by Rhubarb (Rhizomes of Rheum tanguticum) and 5-Lipoxygenase Inhibition of its Major Constituent, Emodin. Phytother Res 2011, 25(5): 755-759.
14. Zhang L, Chen J, Jiang D, Zhang P. Adjuvant treatment with crude rhubarb for patients with systemic inflammation reaction syndrome/sepsis: A meta-analysis of randomized controlled trials. J Crit Care 2015; 30(2): 282-289.

15. SHN Moorthy N, J Ramos M, A Fernandes P. Studies on a-glucosidase inhibitors development: magic molecules for the treatment of carbohydrate mediated diseases. Mini Rev. Med. Chem. 2012; 12(8): 713-720.

16. McCue P, Kwon $Y$-I, Shetty $K$. Anti-diabetic and antihypertensive potential of sprouted and solid-state bioprocessed soybean. Asia PacJClin Nutr 2005; 14(2): 145-152.

17. Aichner D, Ganzera M. Analysis of anthraquinones in rhubarb (Rheum palmatum and Rheum officinale) by supercritical fluid chromatography. Talanta 2015; 144: 1239-1244.

18. Meng P, Xie C, Geng P, Qi X, Zheng F, Bai F. Inhibitory effect of components from Streptomyces species on $\alpha$ glucosidase and $\alpha$-amilase of different origin. ApplBiochem Microbiol 2013; 49(2): 160-168.

19. Mojica L, Meyer A, Berhow MA, de Mejía EG. Bean cultivars (Phaseolus vulgaris L.) have similar high antioxidant capacity, in vitro inhibition of a-amylase and $\alpha$-glucosidase while diverse phenolic composition and concentration. Food ResInt 2015; 69: 38-48. 